\title{
Monitoring of activated sludge settling ability through image analysis: validation on full-scale wastewater treatment plants
}

\author{
D. P. Mesquita · O. Dias · A. L. Amaral · \\ E. C. Ferreira
}

Received: 29 May 2008/Accepted: 6 August 2008/Published online: 23 August 2008

(C) Springer-Verlag 2008

\begin{abstract}
In recent years, a great deal of attention has been focused on the research of activated sludge processes, where the solid-liquid separation phase is frequently considered of critical importance, due to the different problems that severely affect the compaction and the settling of the sludge. Bearing that in mind, in this work, image analysis routines were developed in Matlab environment, allowing the identification and characterization of microbial aggregates and protruding filaments in eight different wastewater treatment plants, for a combined period of 2 years. The monitoring of the activated sludge contents allowed for the detection of bulking events proving that the developed image analysis methodology is adequate for a continuous examination of the morphological changes in microbial aggregates and subsequent estimation of the sludge volume index. In fact, the obtained results proved that the developed image analysis methodology is a feasible method for the continuous monitoring of activated sludge systems and identification of disturbances.
\end{abstract}

Keywords Activated sludge - Image analysis · Aggregates $\cdot$ Filaments $\cdot$ Settling ability

D. P. Mesquita - O. Dias · A. L. Amaral · E. C. Ferreira $(\square)$

IBB, Institute for Biotechnology and Bioengineering,

Centre of Biological Engineering, Universidade do Minho, Campus de Gualtar, 4710-057 Braga, Portugal

e-mail: ecferreira@deb.uminho.pt

\section{A. L. Amaral}

Instituto Superior de Engenharia de Coimbra, Instituto Politécnico de Coimbra, Rua Pedro Nunes, Quinta da Nora, 3030-199 Coimbra, Portugal

\section{Introduction}

Biological processes are very sensitive to external and internal variations, affecting their optimum working conditions. In activated sludge systems, an adequate balance between the different types of bacteria is essential to ensure an efficient pollution removal, good settling ability of the sludge and low suspended solids effluent levels. After the oxidation of the organic matter in the aerated tank, the flocculated biomass is separated from the treated effluent by means of their settling ability in a settling tank. The settling phase is considered a critical stage of the process in which filamentous bulking and deflocculation processes are the most common problems, causing the decrease of the sludge settling ability and effluent quality deterioration [1-7].

The solid-liquid separation in wastewater treatment plants (WWTPs) is commonly assessed through the sludge volume index (SVI) evaluation, characterizing the sludge settling ability. However, as the SVI only provides a macroscopic evaluation of the activated sludge, the microscopic characteristics of the sludge should be also determined by examination under an optical microscope. Therefore, it comes as no surprise that microscopic image analysis procedures have been used, in recent years, to complement the wastewater treatment processes mainly on the morphological characterization and evaluation of aggregated and filamentous bacteria contents. As the activated sludge process efficiency is dependent on the aggregates physical properties, some basic parameters have been used to study the settling ability of the microbial aggregates such as the filamentous bacteria contents, aggregates contents, size, shape, density, porosity and settling velocity, as well as consistency and specific surface area [8-10]. In fact, image analysis procedures are, 
nowadays, considered to be a feasible method to characterize quantitatively aggregates and protruding filamentous bacteria, and subsequently used to relate to the settling abilities [11-16], assess biomass morphology changes and monitor bulking events in pilot and full-scale plants [14, 17, 18].

Following past studies [14, 18, 19], the present work aims to survey the filamentous bacteria and aggregates contents and morphology of the biomass collected from eight full-scale WWTPs during a combined period of 2 years. For that purpose, an image processing and analysis program was developed for bright field microscopy, providing the necessary data for monitoring the biological system. The results based on image analysis procedures will be related on one hand to the operating conditions, and on the other, with the reported events in the WWTPs.

\section{Materials and methods}

The biomass used in this study was collected from the aeration basins of eight WWTPs (Sobreposta, Frossos1, Cunha, Tadim, Ucha, Pousa, Oliveira and Frossos2), treating domestic effluents, located in the North of Portugal. Samples were taken to perform physical measurements, on one hand, and microscopic observations, on the other, in order to estimate the contents and morphology of the microbial aggregates and protruding filamentous bacteria by image acquisition and analysis. The biomass settling ability was measured through the determination of the SVI in a $10 \mathrm{~L}$ cylindrical column $(15 \mathrm{~cm}$ diameter), with the sludge height variation monitored for $30 \mathrm{~min}$. Total suspended solids were determined by weight, and used to determine the SVI parameter [20].

Image acquisition

For each sample, a volume of $25 \mu \mathrm{L}$ was placed on a slide and covered with a $20 \mathrm{~mm} \times 20 \mathrm{~mm}$ cover slip for visualization and image acquisition for all the surveyed WWTPs. The volume deposition was performed by means of a recalibrated micropipette with a sectioned tip at the end to a diameter allowing the passage of even the larger aggregates. For each monitored day three individual sample slides were obtained for each sample and screened in the upper, median and lower third each, with images grabbed for each four fields of view.

Except for Frossos2, around 200 images per sample were acquired in bright field microscopy to obtain representative information of the sludge. All the images were acquired in a Leitz Laborlux S optic microscope (Leitz, Wetzlar), with $100 \times$ magnification, coupled to a Zeiss AxioCam HRc (Zeiss, Oberkochen) camera. The image acquisition was performed in $1,300 \times 1,030$ pixels and 8 bit format through the AxioVision 3.1 (Zeiss, Oberkochen) software.

The image acquisition of the Frossos2 WWTP, had already been performed for an earlier study and, relied on 20 images per sample acquired in bright field microscopy in a SZ 4045TR-CTV Olympus stereo microscope (Olympus, Tokyo), with $40 \times$ magnification, coupled to a Sony CCD AVC-D5CE (Sony, Tokyo) grey scale video camera. The image acquisition was performed in $768 \times 576$ pixels and 8-bit format by a Data Translation DT 3155 (Data Translation, Marlboro) frame grabber using the commercial software package Image Pro Plus (Media Cybernetics, Silver Spring).

Image processing and analysis methodology

The image processing and analysis program for aggregates and filaments, was developed in Matlab 7.3 (The Mathworks, Inc., Natick) language, adapting a previous version developed by Amaral and Ferreira [18]. Primarily, the image processing step determined the binary images from the aggregated biomass and the protruding filamentous bacteria and thereafter, the morphological parameters were determined. Figure 1 shows an example of the original, binary and labeled images resulting of the main steps of the program, comprising the image pre-treatment, segmentation, and debris elimination whereas the image analysis program was oriented to the aggregates and filaments contents determination.

Image analysis parameters

Supported on the previous study of Amaral and Ferreira [18], 36 parameters were determined either directly from the image analysis program either in association with the sludge physical properties for a total around 400000 aggregates. Total aggregates number per sludge volume, total aggregates area per sludge volume, aggregates area, total filaments length per sludge volume, filaments length, aggregates length, aggregates perimeter and aggregates equivalent diameter were determined for all the samples collected. The morphological descriptors convexity, solidity, roundness, and eccentricity were also determined by the image analysis methodology. Furthermore, the aggregates characterization was subsequently divided in three classes in order to differentiate between small low settling structures (contained within the aggregates below $0.025 \mathrm{~mm}$ in equivalent diameter), normal sized good settling structures (between 0.025 and $0.25 \mathrm{~mm}$ in equivalent diameter), and large connected low settling structures (contained within the aggregates above $0.25 \mathrm{~mm}$ in equivalent diameter). The total filaments length per sludge 
Fig. 1 Original image from the activated sludge system with $\times 100$ magnification (a), binary aggregates image (b), binary filaments image (c) and final labeled image (d)
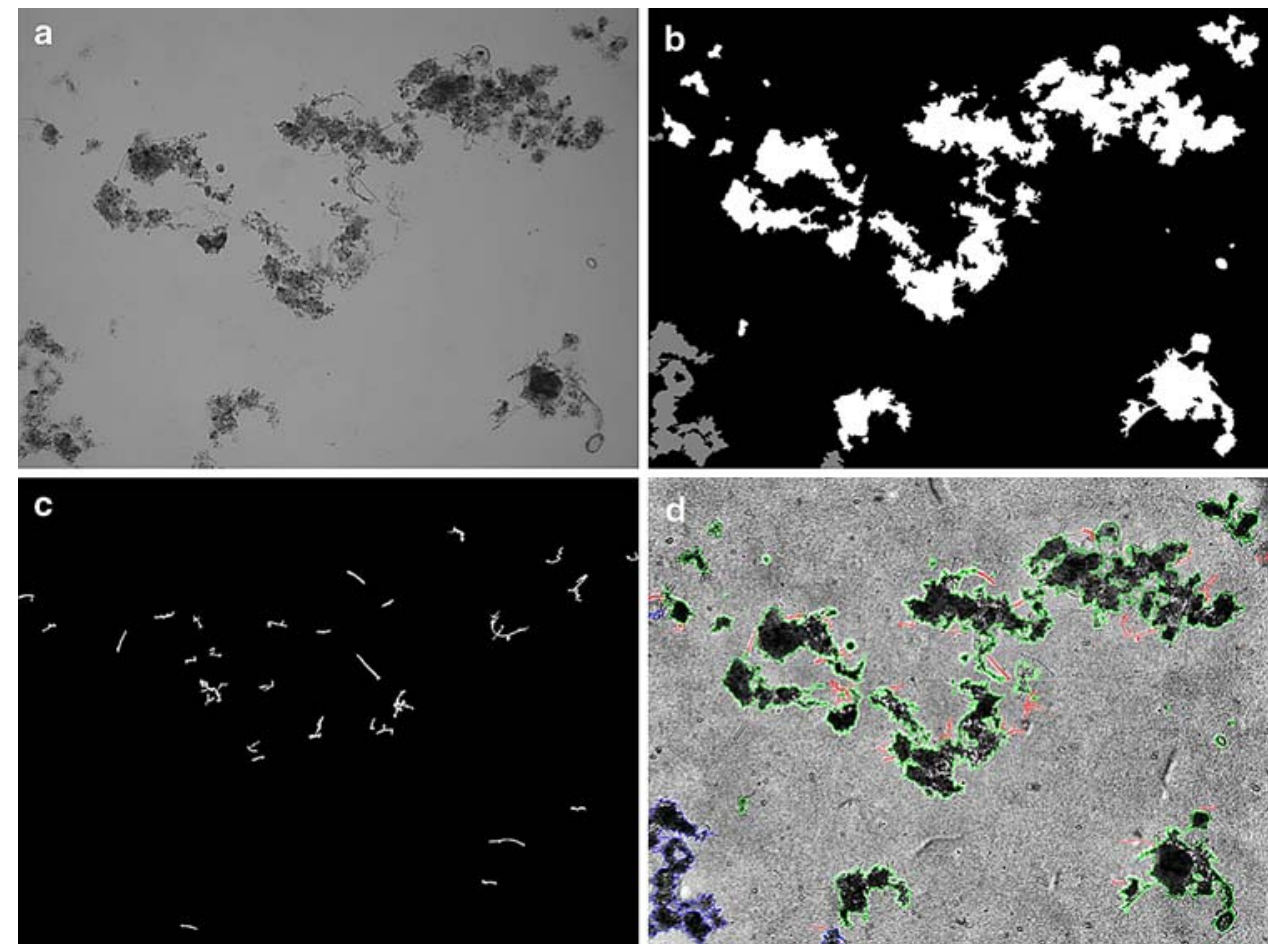

volume, filaments average length per aggregates average area ratio, filaments average length per aggregates average equivalent diameter ratio and the total filaments length per total aggregated area ratio were determined alongside the total filaments length per volatile suspended solids ratio characterizing the filaments dynamics. A more detailed description of each parameter can be found in Amaral [19]. It should also be pointed out that a study [21] has also been conducted regarding the reduction of the parameters number for the best nine parameters, representing the free filamentous bacteria contents and characterization and aggregates contents, size and morphology, yielding satisfying results (reduction of only 0.034 on the correlation coefficient). Therefore, the use of the reduced data set may lead to a decreased correspondence between the predicted and observed SVI although not significantly far apart from the ones reported here.

\section{Partial least squares}

The collected data set $(5,184$ data points from 144 samples $\times 36$ parameters) was correlated by Partial Least Squares (PLS) regression, an iterative algorithm that extracts linear combinations of the essential features of the original $X$ data while modeling the $Y$ data dependence on the work set, being therefore well suited for multivariate calibration. PLS have been shown to be an efficient approach in monitoring complex processes since the high dimensional strongly cross-correlated data can be reduced to a much smaller and interpretable set of latent variables [22]. To perform the PLS analysis from the data set, SIMCA 8.0 (Umetrics, Umëa) software package was used. SIMCA computes the variable importance in the projection (VIP) as the sum over all model dimensions (PLS components) of the variable influence. The parameters that are found to be the most important are the ones presenting a VIP value larger than 1. A more detailed description about this method can be found in Umetri [23].

\section{Results and discussion}

The PLS analysis allowed to predict the SVI values from the image analysis data with a reasonable correspondence as it can be seen in Fig. 2. Analyzing the results it was found that the multiple correlation coefficient (goodness of fit) attained for the SVI prediction was $0.947\left(R^{2}\right.$ of 0.897$)$, allowing to predict, at some extent, the SVI values from the obtained image analysis data.

It must be noticed that, above the $200 \mathrm{~mL} / \mathrm{g}$ SVI threshold, there seems to be a higher dispersion regarding the observed versus the predicted results and, hence, the accuracy of the prediction will not be as high as for lower SVI values. However, this behavior may be explained by the fact the majority of the data points above $200 \mathrm{~mL} / \mathrm{g}$ were acquired in a previous study with an acquisition of an average of 20 images per sample (acquisition for Frossos2 WWTP) instead of the average 200 images for the other 


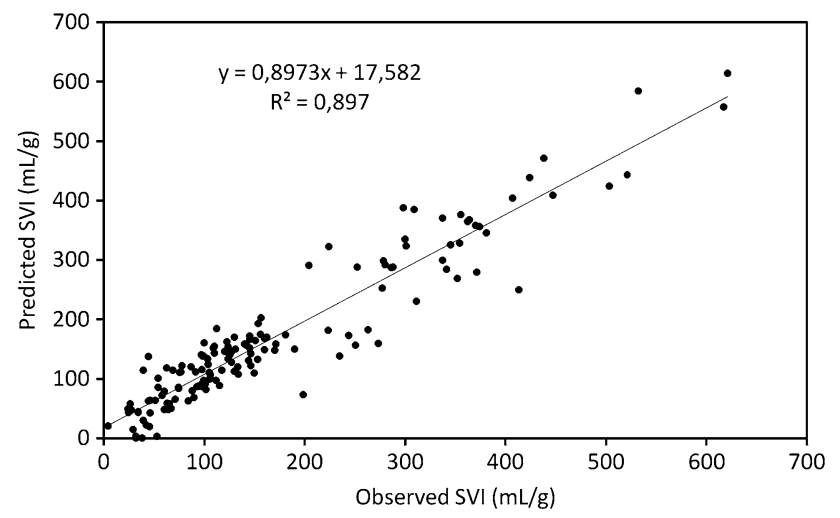

Fig. 2 Global correlation between the observed and predicted SVI data points

WWTPs. In accordance to this explanation, no significant correlations were found between the errors of the predicted SVI and the SVI values within the Frossos 2 data set $\left(R^{2}\right.$ of $0.0171)$ and between the errors of the predicted SVI and the SVI values within the remaining WWTP data set $\left(R^{2}\right.$ of 0.0004).

The observed SVI values were monitored throughout eight different WWTPs and are presented in Fig. 3, alongside the predicted SVI values. From the analysis of this figure it can be perceived that the predicted SVI values follow, at some extent, the observed SVI trends corroborating the findings of the PLS analysis results. Furthermore, it was found that the observed and predicted SVI values differ between each other around $31 \mathrm{~mL} / \mathrm{g}$ in average. It was also found that the difference between the values is smaller for the lower SVI values, around $24 \mathrm{~mL} / \mathrm{g}$ for the set of SVI values below $200 \mathrm{~mL} / \mathrm{g}$, and larger for higher SVI values, around $49 \mathrm{~mL} / \mathrm{g}$ for the set of SVI values above $200 \mathrm{~mL} / \mathrm{g}$. Once again this behavior may be explained by the fact the majority of the data points above $200 \mathrm{~mL} / \mathrm{g}$ rely on an average of 20 images per sample

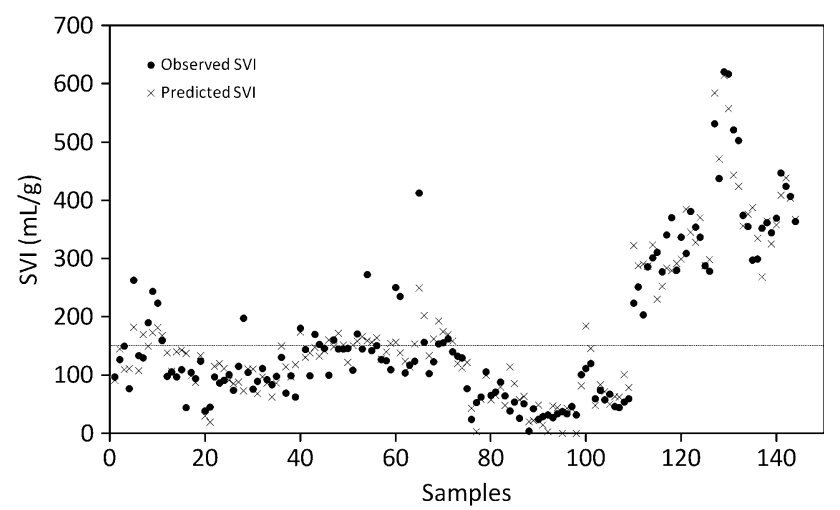

Fig. 3 Global observed and predicted SVI data points from the WWTP aerated tanks instead of the average 200 images for the data points below $200 \mathrm{~mL} / \mathrm{g}$.

In most cases for the SVI below the bulking limit ( $150 \mathrm{~mL} / \mathrm{g}$ according to Jenkins et al. [5]) there is a correspondence to the predicted SVI (presenting also values below $150 \mathrm{~mL} / \mathrm{g}$ ). An analogous trend is also found for the values indicating bulking phenomena with predicted SVI values above the $150 \mathrm{~mL} / \mathrm{g}$ limit. In fact for the 89 data points that presented SVI values below $150 \mathrm{~mL} / \mathrm{g}$, this methodology correctly predicted $77(86.5 \%)$ of these as non-bulking situations, whereas for the 55 data points presented SVI values above $150 \mathrm{~mL} / \mathrm{g}$, this methodology correctly predicted $49(89.1 \%)$ of these as bulking situations. Given the $24 \mathrm{~mL} / \mathrm{g}$ uncertainty for the SVI values below $200 \mathrm{~mL} / \mathrm{g}$ and the fact that the bulking limit is set on $150 \mathrm{~mL} / \mathrm{g}$, a closer analysis of the values outside this uncertainty area $(150 \pm 24 \mathrm{~mL} / \mathrm{g})$ reveals that only 6 (6.7\%) values below the lower limit and $3(5.5 \%)$ values above the upper limit are incorrectly classified.

For an in-depth analysis of each of the WWTP, their individual SVI values (observed and predicted) are represented in Fig. 4. From this figure, it can be withdrawn that the eight aerated tanks have different operating conditions, and some with strong fluctuations in terms of the sludge settling abilities.

For Sobreposta WWTP, the SVI results, here depicted on Fig. $4 \mathrm{a}$, presented values mainly below the $150 \mathrm{~mL} / \mathrm{g}$ threshold limit for bulking events. Only 5 days (days 28 , 49, 56, 63 and 70) presented SVI values higher than $150 \mathrm{~mL} / \mathrm{g}$ (bulking phenomena), ranging from 160 to $265 \mathrm{~mL} / \mathrm{g}$. The predicted values for this WWTP were, for the most, in accordance with the observed SVI values with larger deviations occurring on days 28, 56 and 105 (all above $50 \mathrm{~mL} / \mathrm{g}$ ). With respect to the bulking prediction ability, only 2 days (out of 23) were incorrectly classified, with one of those days falling into the uncertainty area $(150 \pm 24 \mathrm{~mL} / \mathrm{g})$, thus meaning that only 1 day was effectively misclassified.

The SVI behavior in Frossos1 WWTP, depicted on Fig. 4b, revealed a non-bulking system with the only exceptions on days 14 and 149 with 198 and $181 \mathrm{~mL} / \mathrm{g}$, respectively. The predicted values for this WWTP were, for the most, in accordance with the observed SVI values with larger deviations occurring on days 14 and 128 (above $50 \mathrm{~mL} / \mathrm{g}$ ). With respect to the bulking prediction ability, only 1 day (out of 17) was misclassified, falling outside the uncertainty area $(150 \pm 24 \mathrm{~mL} / \mathrm{g})$.

Regarding the Cunha WWTP (Fig. 4c), the SVI values were always on the threshold of configuring a bulking phenomenon and in days 14, 21, 64, 98 and 112 were, in fact, higher than $150 \mathrm{~mL} / \mathrm{g}$. Furthermore, in the last monitored day, the settling properties of the biomass suffered a sudden deterioration with an SVI value of $273 \mathrm{~mL} / \mathrm{g}$. 
Fig. 4 Observed and predicted SVI data points from the eight WWTP aerated tanks.

a Sobreposta, b Frossos1, c Cunha, d Tadim, e Ucha, f Pousa, g Oliveira, h Frossos2
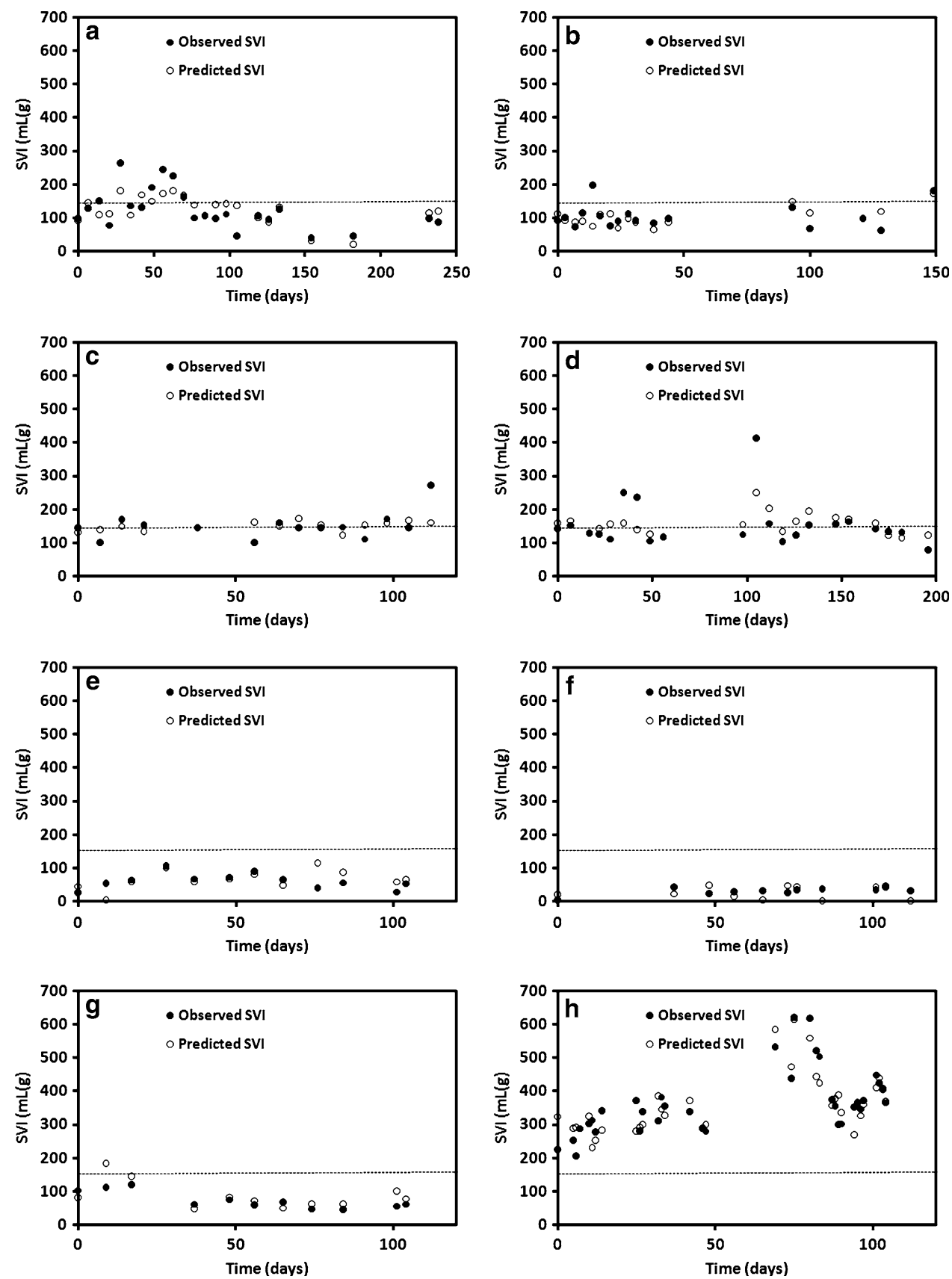

Again, the predicted values for this WWTP were, for the most, in accordance with the observed SVI values with larger deviations occurring on days 56 and 112 (above $50 \mathrm{~mL} / \mathrm{g}$ ). With respect to the bulking prediction ability, 8 days (out of 14) were incorrectly classified, but six of those days fell into the uncertainty area $(150 \pm 24 \mathrm{~mL} / \mathrm{g})$, thus meaning that only 2 days were effectively misclassified.

The SVI behavior of Tadim WWTP is depicted on Fig. 4d, showing values around the threshold limit for bulking events although such was not the case for a few periods of the survey. In fact, for day 7, day 112 and from day 133 to 154 the plant presented mild bulking phenomena, and for days 35 to 42 and day 105 considerable bulking problems. It was found a good correspondence between the predicted and observed SVI values for this WWTP, with larger deviations occurring only on days 35 , 42 and 105 (above $50 \mathrm{~mL} / \mathrm{g}$ ). With respect to the bulking prediction ability, 6 days (out of 21) were incorrectly classified, with two of those days falling into the uncertainty area $(150 \pm 24 \mathrm{~mL} / \mathrm{g})$, thus meaning that 4 days were effectively misclassified.

Regarding the Ucha WWTP (Fig. 4e), low SVI values predominated throughout the survey, as the SVI remained below the bulking threshold $(150 \mathrm{~mL} / \mathrm{g})$ during all the 
monitoring period. Such was also the case of the Pousa WWTP (below $50 \mathrm{~mL} / \mathrm{g}$ ) and Oliveira WWTP (between 40 and $120 \mathrm{~mL} / \mathrm{g}$ ), depicted on Fig. 4f, g, respectively. Once more, the predicted values for these WWTPs were in accordance with the observed SVI values with a larger deviation (above $50 \mathrm{~mL} / \mathrm{g}$ ) occurring solely on day 9 of the Oliveira WWTP. With respect to the bulking prediction ability, only 1 day (out of 34) was misclassified, falling outside the uncertainty area $(150 \pm 24 \mathrm{~mL} / \mathrm{g})$.

The SVI behavior in Frossos2 WWTP, depicted on Fig. $4 \mathrm{~h}$, revealed a bulking problem, throughout all the monitoring period, with values ranging from 204 up to $617 \mathrm{~mL} / \mathrm{g}$. It was found a reasonable correspondence between the predicted and observed SVI values for this WWTP with larger deviations (above $50 \mathrm{~mL} / \mathrm{g}$ ) occurring on 12 of the 35 days (days 1, 6, 11, 14, 25, 32, 69, 80, 82, 83, 89 and 94). Again it should be emphasized the fact that this WWTP data points rely on an average of 20 images per sample instead of the average 200 images for the remaining WWTP, hence, explaining the poorer correspondence between the predicted and observed SVI values. However, and with respect to the bulking prediction ability, not a single day (out of 35) was incorrectly classified. Furthermore, it should also be stressed that, the predicted SVI followed the observed SVI behavior throughout all the monitoring period.

In a global analysis, it should also be noticed that, the two WWTP that were chronically on the threshold of bulking events (Cunha and Tadim) accounted for 14 of the 18 days incorrectly classified, and taking into account the uncertainty area $(150 \pm 24 \mathrm{~mL} / \mathrm{g})$ for 6 of 9 days effectively misclassified.

\section{Conclusions}

The PLS analysis of the image analysis data allowed to predict the SVI values with a reasonable correspondence as it can be inferred by the 0.947 multiple correlation coefficient obtained between the observed and predicted SVI values. It should be kept in mind, however, that although the obtained correlation holds true for the SVI range presented in the surveyed WWTPs (up to $700 \mathrm{~mL} / \mathrm{g}$ ) no direct extrapolations can be performed for higher SVI values regarding severe bulking phenomena.

It was also found that, for the current methodology, the observed and predicted SVI values distanced from each other an average $24 \mathrm{~mL} / \mathrm{g}$ for the set of SVI values below $200 \mathrm{~mL} / \mathrm{g}$, which comprises the bulking threshold limit. This fact allowed the establishment of an uncertainty area $(150 \pm 24 \mathrm{~mL} / \mathrm{g})$ regarding the effectiveness of classifying bulking/non-bulking situations. That being the case, the results revealed that only 9 out of $144(6.3 \%)$ outside the uncertainty area were, in fact, incorrectly classified according to this methodology.

In conclusion, the obtained results showed that the developed image analysis and PLS methodology proved to be adequate for continuous examination of sludge settling properties, in terms of the SVI. Furthermore, this methodology was able to predict, for the most part, the disturbances within the aerated tank of eight different WWTPs.

Acknowledgments The authors gratefully acknowledge the financial support to Daniela Mesquita and Oscar Dias through the grant SFRH/BD/32329/2006 and the project POCI/AMB/57069/2004, respectively, provided by Fundação para a Ciência e Tecnologia (Portugal). The authors express their gratitude to AGERE (Empresa de Águas, Efluentes e Resíduos de Braga, Portugal-EM) and Rui Gonçalves for their cooperation.

\section{References}

1. Sezgin M, Jenkins D, Parker D (1978) A unified theory of filamentous activated sludge bulking. J Water Pollut Control Fed $50: 362-381$

2. Sezgin M (1982) Variation of sludge volume index with activated sludge characteristics. Water Res 16:83-88

3. Ganczarczyk JJ (1994) Microbial aggregates in wastewater treatment. Water Sci Technol 30:87-95

4. Li X, Yuan Y (2002) Settling velocities and permeabilities of microbial aggregates. Water Res 36:3110-3120

5. Jenkins D, Richard MG, Daigger G (2003) Manual on the causes and control of activated sludge bulking, foaming and other solids separation problems. Lewis publishing, Boca Raton

6. Schuler AJ, Jang H (2007) Causes of variable biomass density and its effects on settling in full scale biological wastewater treatment systems. Environ Sci Technol 41(5):1675-1681

7. Schuler AJ, Jang H (2007) Density effects on activated sludge zone settling velocities. Water Res 41(8):1814-1822

8. Cenens C, Jenné R, Van Impe JF (2002) Evaluation of different shape parameters to distinguish between flocs and filaments in activated sludge images. Water Sci Technol 45(4-5):85-91

9. Cenens C, Van Beurden KP, Jenné R, Van Impe JF (2002) On the development of a novel image analysis technique to distinguish between flocs and filaments in activated sludge images. Water Sci Technol 46(1-2):381-387

10. Jenné R, Banadda EN, Gins G, Deurinck J, Smets IY, Geeraerd AH, Van Impe JF (2006) Use of image analysis for sludge characterisation: studying the relation between floc shape and sludge settleability. Water Sci Technol 54(1):167-174

11. Grijspeerdt K, Verstraete W (1997) Image analysis to estimate the settleability and concentration of activated sludge. Water Res 31:1126-1134

12. Banadda EN, Smets IY, Jenné R, Van Impe JF (2005) Predicting the onset filamentous bulking in biological wastewater treatment systems exploiting image analysis information. Bioprocess Biosyst Eng 27:339-348

13. Jenné R, Banadda EN, Smets IY, Deurinck J, Van Impe JF (2007) Detection of filamentous bulking problems: developing an image analysis system for sludge composition monitoring. Microsc Microanal 13:36-41

14. da Motta M, Amaral AL, Casellas M, Pons MN, Dagot C, Roche N, Ferreira EC, Vivier H (2001a) Characterisation of activated sludge by automated image analysis: validation on full-scale 
plants. In: Proceedings of the IFAC computer applications in biotechnology, Québec City, pp 427-431

15. Jenné R, Banadda EN, Philips N, Van Impe JF (2003) Image analysis as a monitoring tool for activated sludge properties in lab-scale installations. J Environ Sci Health A Tox Hazard Subst Environ Eng 38(10):2009-2018

16. Jenné R, Banadda EN, Smets IY, Van Impe JF (2004) Monitoring activated sludge settling properties using image analysis. Water Sci Technol 50(7):281-285

17. da Motta M, Pons MN, Roche N (2001) Automated monitoring of activated sludge in a pilot plant using image analysis. Water Sci Technol 43(7):91-96

18. Amaral AL, Ferreira EC (2005) Activated sludge monitoring of a wastewater treatment plant using image analysis and partial least squares regression. Anal Chim Acta 544:246-253
19. Amaral AL (2003) Image analysis in biotechnological processes: applications to wastewater treatment. PhD Thesis, Braga, Portugal, 2003. http://hdl.handle.net/1822/4506

20. APHA, AWWA, WPCF (1989) Standard methods for the examination of water and wastewater, 17th edn. American Public Health Association, Washington

21. Mesquita DP, Dias O, Dias AMA, Amaral AL, Ferreira EC (2008) Correlation between sludge settleability and image analysis information using partial least squares. Proceedings of the 11th conference on chemometrics in analytical chemistry, Montpellier, vol 4, pp 175-179

22. Teppola P, Mujunen S-P, Minkkinen P (1997) Partial least squares modeling of an activated sludge plant: a case study. Chemmom Intell Lab Syst 38:197-208

23. Umetri AB (1998) User's guide to SIMCA. CD-ROM 